\title{
Ketamine and xylazine combinations for short-term immobilization of wild variable flying foxes (Pteropus hypomelanus).
}

\begin{abstract}
Collection of biological samples from pteropid bats requires chemical restraint of the bats to minimize risks to humans and stress to the bat. The effectiveness of an intravenous combination of ketamine and xylazine for short-term restraint of wild-caught variable flying foxes (Pteropus hypomelanus) in a field situation was evaluated. Eight adult male variable flying foxes were injected intravenously with $0.1 \mathrm{ml}$ of ketamine and xylaxine containing 5 $\mathrm{mg}$ of ketamine and $1 \mathrm{mg}$ of xylazine. The mean induction time was $8020 \mathrm{sec}$, and mean immobilization time was $2610 \mathrm{~min}$. The ketamine-xylazine combination used in this study produced effective short-term immobilization of wild variable flying foxes for the collection of biological samples.
\end{abstract}

Keyword: Immobilization; Ketamine; Pteropus hypomelanus; Variable flying fox; Xylazine. 